\title{
Study of HIV Prevalence and Behaviors in Rural Areas of Goudomp Health District (Senegal)
}

\author{
Niang Khadim¹, Anne Malick², Sarr Assane², Thiam Ousmane ${ }^{3}$, Ndiaye Papa1 \\ ${ }^{1}$ Public Health Department, Gaston Berger University (UGB) of Saint-Louis, Saint-Louis, Senegal \\ ${ }^{2}$ Goudomp Health District, Sedhiou Region, Senegal \\ ${ }^{3}$ Obstetrics and Gynecology Department, Gaston Berger University (UGB) of Saint-Louis, Saint-Louis, Senegal \\ Email: khadimniang@outlook.com
}

How to cite this paper: Khadim, N., Malick, A., Assane, S., Ousmane, T. and Papa, N. (2020) Study of HIV Prevalence and Behaviors in Rural Areas of Goudomp Health District (Senegal). World Journal of AIDS, 10, 69-79.

https://doi.org/10.4236/wja.2020.102006

Received: January 17, 2020

Accepted: May 4, 2020

Published: May 7, 2020

Copyright (c) 2020 by author(s) and Scientific Research Publishing Inc. This work is licensed under the Creative Commons Attribution International License (CC BY 4.0).

http://creativecommons.org/licenses/by/4.0/

\begin{abstract}
This study aims to determine the factors related to HIV-positive status in people aged 15 to 49 years of age in the commune of Niagha in Goudomp. The study was descriptive and analytically cross-cutting and had taken place in a release of 2018. The data was collected on anonymous questionnaires and then analyzed using $\mathrm{R}$ software after entering with Epi 7 software. Bivariate analyses and logistical modelling have been used to investigate the factors associated with HIV status. The sample included 400 people, and a participation rate of $100 \%$ was obtained in relation to the administration of the questionnaire. For the detection of HIV infection, 318 people agreed to do so, a proportion of $79.7 \%$. The average age of the respondents was 27.8 years with a standard deviation of 9.1 and extremes of 15 to 49 years. $21.5 \%$ of respondents were under 20 years of age, the median was 26 years. With $58.8 \%$ of women, the sex ratio $(\mathrm{M} / \mathrm{F})$ was 0.7 . In this study, $11.5 \%$ of respondents did not believe in the existence of HIV infection, $92.0 \%$ were sexually active, and $40.5 \%$ had sex with casual partners. The main places for casual sex were cultural events $(84.0 \%)$, weekly markets $(53.1 \%)$, religious events $(27.8 \%)$ and during travel (22.8\%). Among them, only 20 respondents, or $12.3 \%$, declared that they systematically protect themselves with a condom during these occasional sexual relations. This wearing of condoms was found in $20.7 \%$ of singles and $10.7 \%$ of married couples having casual sex. In this study, $60.0 \%$ of the respondents declared that they had paid for sex, although this practice is not cited in income-generating activities. Non-consensual sex was found in $6.5 \%$ of the respondents. In this study, 319 people agreed to be tested for HIV, or $79.7 \%$ of the sample. HIV infection was found in 19 people, $6.0 \%$ seroprevalence, with 16 cases of HIV 1 infection and three cases of HIV 2 infection. Several risk behaviors were found in this study. However, none of them had a statistically significant link to HIV seropositivity. The prevalence of
\end{abstract}


HIV infection in Niagha common is very high compared to data from the Sedhiou region and national level. Risky sexual behaviors are found in this population with no statistically significant link to HIV. Studies with a mixed approach would be more appropriate to study these relationships.

\section{Keywords}

HIV, Risky Behaviors, IST, Prevalence, Senegal

\section{Introduction}

HIV infection is a real global public health problem. According to UNAIDS, worldwide at the end of 2017, 36.9 million people were living with HIV and 940,000 died from related causes. IN 2005 the mortality was 2 million [1].

The HIV pandemic presents great variations according to world geographical zones, sub-Saharan Africa being the most affected region with more than $66 \%$ of new infections [2]. The countries of southern and eastern Africa are the epicenter of the worldwide pandemic. Most appear to have stabilized, although often at very high levels. This is particularly the case for South Africa (17.9\%), Botswana (23.4\%) and Swaziland (24.8\%) [2].

In Senegal, the 2017 Demographic and Health Survey [3] found an overall HIV prevalence of $0.5 \%$ in the general population. In the Sedhiou region, HIV infection is concentric with a prevalence of $1.8 \%$ in the general population, $3.8 \%$ in MSM, 6.6\% in PS, and 5.2\% in the UID [4].

The Goudomp district follows in the same wake, with a positivity of $1.1 \%$ in 2016 and $1.52 \%$ in 2017. In the commune of Niagha, despite 17 advanced strategies implemented in 2017 as part of the prevention of HIV infection, 1462 people benefited from HIV infection screening tests, with a HIV positive rate of $6.5 \%$. At the level of the Goudomp health district, of the 120 new cases of HIV infection detected in 2017, 80\% came from the single commune of Niagha [5]. The high prevalence in the commune of Niagha thus suggests the existence of specific vulnerability factors which are at the root of practices exposing people to the risk of HIV infection.

In order to improve the health of populations in general, this study will be conducted to identify the factors associated with HIV seropositivity in people aged 15 - 49 years living in the commune of Niagha.

\section{Methodology}

\subsection{Study Framework}

The study took place in the commune of Niagha which is one of the 15 communes in the department of Goudomp, located in Casamance, in the south of Senegal.

The municipality of Niagha had an estimated population of 14,257 inhabitants 
in 2018 , of which $24 \%$ were women of reproductive age.

The department of Goudomp borders on the region of Kolda which presents, together with the region of Ziguinchor, the highest prevalence in the country, estimated at $1.5 \%$ in 2017 [3]. It also shares geographical limits with the Republic of Guinea and Guinea Bissau which are countries with higher prevalence than those observed in Senegal, of $1.7 \%$ and $3.1 \%$ respectively [2]. The commune of Niagha is the area of the border district with the Kolda region, but also with Guinea Bissau and the Republic of Guinea.

\subsection{Study Type}

The study was transversal, descriptive and analytical and took place in August 2018 .

\subsection{Study Population and Sampling Protocol}

Any person who had all of the following characteristics was included in this study:

- Between 15 and 49 years old;

- Residing in the municipality of Niagha for at least one year before the date of data collection.

People who refused to participate in the study or were unavailable at the time of data collection were not included. The person could accept the questionnaire and refuse the rapid screening test. However, any refusal to administer the questionnaire resulted in exclusion from the study.

The sample size was calculated using the Casagrande \& Pike formula [6]. Since the prevalence of HIV infection in the different groups compared was not known, it was set at $0.3 \%$ and $5 \%$. The alpha risk was established at $5 \%$, and the beta risk at $20 \%$. A cluster effect of 1.5 and a non-response rate of $25 \%$ (for the screening test) were taken into account. This gave a sample size of 398 people, rounded to 400 .

A three-stage sampling plan was carried out for selection:

- First stage: The first stage survey concerned the selection of villages. At this level all villages were included in the study: it was therefore an exhaustive selection. The number of people to be surveyed was distributed proportionally among the different villages according to their demographic weight.

- Second stage: The second stage of sampling allowed the selection of concessions to be investigated at the village level. At this level, a systematic random survey was used while respecting the proportions between the different villages. At the village level, all of the concessions were numbered. The sampling pitch (interval between two household numbers) was calculated by dividing the total number of concessions in the village by the number of concessions to be surveyed. The first concession to be investigated was identified by drawing a number between the first concession and the number of the survey step, the supervisor drew up the list of concessions to be investigated 
for each village to be investigated.

- Third stage: This level of sampling concerned the selection of statistical units within the concessions. Only one person had to be selected in each concession included. When more than one person met the criteria for inclusion in the same household, a simple random survey was conducted by the interviewer. When the number of statistical units found in the household was equal to 1 , it was selected without drawing.

\subsection{Collection of Data}

A questionnaire was developed for the collection of data from this survey, according to the objectives. This questionnaire included 58 items divided into five chapters:

- Identification;

- Socio-professional characteristics: age, sex, place of residence, marital status, religion, income-generating activity;

- Knowledge about HIV infection: mode of transmission, screening;

- Attitudes and practices related to HIV: STI prevention, attitudes towards patients, screening;

- HIV test: acceptance and result.

The sample for HIV infection screening was done by specialists from the Goudomp laboratory health center, this to ensure the safety of the sample and confidentiality. This involved taking a drop of capillary blood from the fingertip and placing it on the effective area on the Determine ${ }^{\circledR}$ test strip.

In the event of a positive test, a capillary blood sample was taken in the laboratory for the use of the Bioline ${ }^{\circledR}$ and Multisure ${ }^{\circledR}$ tests in order to confirm the profile, in accordance with the directives of the AIDS control division of the Ministry of Health and social action.

Twelve investigators trained in data collection were responsible for conducting the investigation. The questionnaires were administered by a direct interview in the women's own homes.

\subsection{Data Analysis}

The collected data was entered with Epi 7.2. Software then analysed with R.3.3. [7]. Qualitative variables were described with absolute and relative frequencies and quantitative variables by mean and standard deviation.

Crossovers were made to identify the factors associated with HIV infection. These crossovers were carried out only among the respondents who agreed to perform the HIV test. The Chi-square and Student test were used respectively for the comparison of proportions and means by fixing the alpha risk at $5 \%$.

A logistic regression model made it possible to adjust the different co-variates according to a top-down strategy from a complete model. The lrtest (likelihood ratio) and AIC allowed the choice of the latter with the step-down method. Finally, the test of Hosmer-Lemeshow tested the adequacy of the final model [8]. 
Associations were measured by odds ratios with their confidence intervals.

\subsection{Ethical Considerations}

The consent of the interviewees was previously acquired. Respondents were informed of the objectives and constraints of the study, their rights to refuse to participate in the study or to leave it at any time.

Two consents were obtained from the respondents. The first consent concerned the questionnaire data and was collected before the administration of the latter. The second consent obtained after counselling concerned the realization of RDT/HIV and the exploitation of its result. The test result was given to the interviewee by qualified medical personnel.

The anonymity and confidentiality of the data were respected throughout the process of this study.

\section{Results}

The sample included 400 people, and a participation rate of $100 \%$ was obtained in relation to the administration of the questionnaire. For the detection of HIV infection, 318 people agreed to do so, a proportion of $79.7 \%$.

The sample consisted mainly of Muslims (98.0\%), with income-generating activity $(68.0 \%)$ and married $(81.0 \%)$. With $58.8 \%$ of women, the sex ratio (M/F) was 0.7 . Not in school respondents were in the majority $(47.7 \%)$, and $11.5 \%$ of respondents did not believe in HIV infection (Table 1).

The average age of the respondents was 27.8 years with a standard deviation of 9.1 and extremes of 15 to 49 years. $21.5 \%$ of respondents were under 20 years of age, the median was 26 years.

Sex with casual partners was found in $40.5 \%$ of those surveyed. This proportion was $31.9 \%$ for women and $52.7 \%$ for men. The main places for casual sex were cultural events $(84,0 \%)$, weekly markets $(53.1 \%)$, religious events $(27.8 \%)$ and during travel (22.8\%). Among them, only 20 respondents, or $12.3 \%$, declared that they systematically protect themselves with a condom during these occasional sexual relations. This wearing of condoms was found in $20.7 \%$ of singles and $10.7 \%$ of married couples having casual sex.

In this study, 319 people agreed to be tested for HIV, or $79.7 \%$ of the sample. HIV infection was found in 19 people, 6.0\% seroprevalence, with 16 cases of HIV 1 infection and three cases of HIV 2 infection (Table 1).

The mean age was 28.9 years for HIV-positive people and 28.2 years for HIV-negative people. This difference was not statistically significant $(\mathrm{p}=0.75)$. Among people who had casual sex, the seroprevalence was 6.3\%, among those who systematically used condoms, and $6.2 \%$ among those who did not use it systematically. This difference was not statistically significant $(\mathrm{p}=0.66)$.

None of the independent variables studied were associated with seropositivity during the bivariate and multivariate analyses (Table 2).

Analyses among people who had sex with casual partners, seroprevalence was 
Table 1. Characteristics of those surveyed $(n=400)$.

\begin{tabular}{|c|c|c|}
\hline Parameters & $\begin{array}{l}\text { Absolute frequencies } \\
(\mathrm{n})\end{array}$ & $\begin{array}{l}\text { Relative frequencies } \\
\text { (\%) }\end{array}$ \\
\hline \multicolumn{3}{|l|}{ Religion } \\
\hline Muslim & 98.0 & 392 \\
\hline Christian & 2.0 & 8 \\
\hline \multicolumn{3}{|l|}{ Income-generating activity } \\
\hline Yes & 272 & 68.0 \\
\hline No & 128 & 32.0 \\
\hline \multicolumn{3}{|l|}{ Marital status } \\
\hline Single & 74 & 18.5 \\
\hline Married & 324 & 81.0 \\
\hline Divorced & 2 & 0.5 \\
\hline Widow & 0 & 0.0 \\
\hline \multicolumn{3}{|l|}{ Level of education } \\
\hline Not in school & 191 & 47.7 \\
\hline Primary & 121 & 30.3 \\
\hline Secondary & 80 & 20.0 \\
\hline Higher & 8 & 2.0 \\
\hline \multicolumn{3}{|l|}{ Knowledge of transmission routes } \\
\hline Unprotected sex & 344 & 86.0 \\
\hline Mother-to-child transmission & 331 & 82.8 \\
\hline Scarification & 279 & 69.8 \\
\hline Mosquito bite & 264 & 66.0 \\
\hline Syringe sting & 254 & 63.5 \\
\hline Kiss on the mouth & 193 & 48.3 \\
\hline Sharing glasses, cups & 179 & 44.8 \\
\hline Bedding sharing & 151 & 37.8 \\
\hline \multicolumn{3}{|l|}{ Belief in the real existence of HIV } \\
\hline Yes & 354 & 88.5 \\
\hline No & 46 & 11.5 \\
\hline \multicolumn{3}{|c|}{ Knowledge of the possibility of healing } \\
\hline Yes & 132 & 33.0 \\
\hline No & 222 & 55.5 \\
\hline Not applicable & 46 & 11.5 \\
\hline \multicolumn{3}{|l|}{ Knowledge of screening sites } \\
\hline Yes & 387 & 96.8 \\
\hline No & 13 & 3.2 \\
\hline
\end{tabular}




\section{Continued}

Knowledge of a case in the environment

Yes

No

Sexual activity

Yes

No

Sex with casual partners

Yes

No

Pricing of sex

Yes

No

Non-consensual sex

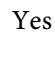

No

HIV testing history

Yes

No

275

125

Acceptance and results of the new screening test

Positive test
Negative test
Refusal of the test

Table 2. Factors associated with HIV infection in bi- and multivariate analysis $(n=319)$.

\begin{tabular}{cccc}
\hline Parameters & $\begin{array}{c}\text { HIV seroprevalence } \\
\mathbf{n}(\%)\end{array}$ & $\begin{array}{c}\text { Khi 2 } \\
\text { p-value }\end{array}$ & $\begin{array}{c}\text { Lrtest } \\
\text { p-value }\end{array}$ \\
Gender & $11(5.9)$ & 0.97 & 0.91 \\
Female & $8(6.0)$ & & \\
Male & & 0.12 & 0.23 \\
Income-generating activity & $16(7.2)$ & & \\
Yes & $3(3.1)$ & & 0.92 \\
No & & & \\
Marital status & $16(6.1)$ & & \\
Married & $3(5.5)$ & & \\
Not married & & & \\
Education & $12(5.4)$ & & \\
Yes & $7(7.4)$ & & \\
No & &
\end{tabular}




\section{Continued}

\begin{tabular}{|c|c|c|c|}
\hline Belief in the real existence of HIV & & 0.21 & 0.36 \\
\hline Yes & $15(4.2)$ & & \\
\hline No & $4(8.7)$ & & \\
\hline \multicolumn{4}{|l|}{ Knowledge of the possibility of healing } \\
\hline Yes & $4(3.6)$ & 0.14 & 0.19 \\
\hline Others & $15(7.2)$ & & \\
\hline Knowledge of a case in the environment & & 0.75 & 0.88 \\
\hline Yes & $5(5.3)$ & & \\
\hline No & $14(6.2)$ & & \\
\hline Sex with casual partners & & 0.93 & 0.85 \\
\hline Yes & $8(6.2)$ & & \\
\hline No & $11(6.0)$ & & \\
\hline Pricing of sex & & 0.87 & 0.79 \\
\hline Yes & $5(6.3)$ & & \\
\hline No & $14(5.8)$ & & \\
\hline Non-consensual sex & & 0.13 & 0.18 \\
\hline Yes & $3(13.6)$ & & \\
\hline No & $16(5.5)$ & & \\
\hline
\end{tabular}

$6.2 \%$ for those who systematically used condoms and those who did not use it systematically.

\section{Discussion}

This observational, cross-sectional, comparative, descriptive and analytical study was to identify the factors linked to seropositivity to HIV infection in people aged 15 to 49 years living in the commune of Niagha.

The surveyed population was relatively young with an average age of $27.84 \pm$ 9.1 years. The predominance of women (58.8\%) found in our study is consistent with the stratification of the Senegalese population which includes $50.8 \%$ women [9].

Respondents are mostly married (81\%). The proportion of married in our study is higher than that found in Malicounda (57\%) by Gueye Ndiaye [10] and in Lubumbashi $(54.3 \%)$ by Kabamba [11]. This large proportion of married people could be linked to the fact that marriage in rural areas is a guarantee of social security and respectability.

The epidemic is concentrated in Senegal, with significant disparities by region, gender and age, among others. The southern zone of the country is the most affected with prevalence higher than $1 \%$ in the southwest of the country, with the two most affected regions, the regions of Ziguinchor and Kolda which have a prevalence of $1.5 \%$ when the prevalence is less than $1 \%$ in the rest of the country 
[3] [4].

In our study, the overall seroprevalence (6.0\%) is higher than the seroprevalence of the general population of the country which is $0.5 \%$. This prevalence is also higher than that of the rural community of Malicounda, a rural area in the Thies region which is $0.5 \%$ [10], and that of the Saraya district (1.12\%) in the Kedougou region. [12]. This seroprevalence found in our study is also higher than that of the Sedhiou region which is $0.5 \%$ [3] but corroborates the results of the Goudomp health district which had estimated HIV seroprevalence at $6.5 \%$ across screening campaigns [5]. Age was not a factor associated with HIV status, which is consistent with the results of other studies in Senegal and the Congo [13] [14].

Sexual transmission is the best-known route of transmission as well as mother-to-child transmission unlike other studies conducted in Senegal for which mother-to-child transmission was sparsely known [10] [12] [15]. Nevertheless, erroneous knowledge on the modes of transmission is noted in our study. In fact, transmission by mosquito bite, sharing of glasses or cups and sharing of bedding were considered as modes of transmission by more than $35 \%$ of the sample. This constitutes wrong beliefs that could lead to stigma of people living with HIV. However, $11.5 \%$ of those surveyed do not believe in the existence of HIV infection.

In our study, $92 \%$ of respondents were sexually active, and $40.5 \%$ had sex with casual partners. Rallies (cultural, commercial and religious were the main events in which these casual sexual relations took place. In addition to having sex with casual partners, only $12.3 \%$ systematically used a condom during this sexual intercourse, which constitutes risky behaviors for the various sexually transmitted infections.

In this study, $60.0 \%$ of the respondents declared that they had paid for sex, although this practice is not cited in income-generating activities. This poses the problem of clandestine prostitution. Indeed, according to the report of the combined surveillance survey [16]. 57.8\% of female sex workers were illegal immigrants. This proportion being higher in rural areas could explain the extent of intercourse paid for in our study, but not declared as an income-generating activity. It also testifies to the precariousness and vulnerability that reigns in these environments thus exposing the populations to unsafe and poorly controlled sexual practices and attitudes which may explain the still high prevalence in the commune of Niagha. This is confirmed by non-consensual sex found in $6.5 \%$ of the respondents.

Several risk behaviors were found in this study. However, none of them had a statistically significant link to HIV seropositivity. A small sample size may be the cause. Indeed, having no information on the proportions to be compared, the fixed proportions thus overestimated the expected differences. For example, for the comparison of the proportions of seropositivity according to the existence of income-generating activities, a posteriori calculation gives a power of $40 \%$ on the comparisons. This may explain the absence of statistically significant links 
[17]. This can also be added to the fact that certain socio-cultural characteristics could also be at the origin of this high prevalence of HIV infection in Niagha. It would require qualitative approaches to investigate them. However, this study remains important because it has made it possible to estimate with more than 95\% certainty the real prevalence, in the population of the HIV positive in the commune of Niagha, as well as the frequencies of the various sexual behaviours at risk.

\section{Conclusion}

The prevalence of HIV infection in Niagha commune is very high compared to data from the Sedhiou region and the Goudomp health district. Risky sexual behaviors are found in this population, especially since the commune constitutes a crossroads between several regions of Senegal and bordering countries. The implementation of communication for development interventions becomes essential in order to improve the health of Niagha populations.

\section{Conflicts of Interest}

The authors declare no conflicts of interest regarding the publication of this paper.

\section{References}

[1] Organisation des Nations Unis pour la lutte contre le VIH/SIDA (ONUSIDA) (2017) Fiche d'information sur l'épidémie mondiale de SIDA 2017. ONUSIDA.

[2] Organisation des Nations Unies pour la lutte contre le VIH/Sida (ONUSIDA) (2018) Rapport sur l'épidémie mondiale de SIDA 2017. ONUSIDA.

[3] Agence nationale de la statistique et de la démographie (2018) Enquête démographique et de santé continue 2017. ANSD.

[4] Conseil National de Lutte contre le Sida au Sénégal (CNLS) (2018) Rapport 2017 de situation sur la riposte nationale à l'épidémie de VIH/sida Sénégal: 2018-2022. CNLS Sénégal.

[5] Équipe cadre du district sanitaire de Goudomp (2018) Rapport District sanitaire de Goudomp 2017. District sanitaire de Goudomp.

[6] Casagrande, J.T., Pike, M.C. and Smith, P.G. (1978) An IMPROVED APPROximate Formula for Calculating Sample Sizes for Comparing Two Binomial Distributions. Biometrics, 34, 483-486. https://doi.org/10.2307/2530613

[7] R Core Team (2015) A Language and Environment for Statistical Computing. R Foundation for Statistical Computing, Vienna, Austria. http://www.r-project.org/

[8] Hosmer, D.W. and Lemeshow, S. (1989) Applied Logistic Regression. John Wiley, New York, 307 p.

[9] Agence nationale de la statistique et de la démographie (2014) RGPHAE 2013. ANSD.

[10] Gueye Ndiaye, A. and Faye, C.M. (2009) Dépistage du VIH, de la syphilis, des infections dues à Chlamydia trachomatis et à Neisseria gonorrhoreæ au cours d'une enquête combinée conduite à Malicounda, une zone rurale du Sénégal. Bulletin de la Société de Pathologie Exotique, 102, 150-154. 
[11] Kabamba, N. (2004) Connaissances, attitudes et pratiques en matière de VIH/SIDA à Lubumbashi. Université Simon Kimbangu Thése. Med.

[12] Ndoye, P.S. (2013) Infection à VIH dans le District Sanitaire de Saraya: Prévalences, Connaissances, Attitudes et Pratiques. Thèse Med. Dakar, 154.

[13] Mbendinlombi, C. (2001) Prévalence du VIH et de l'antigène HBS chez les donneurs du sang. Risque résiduel de contamination chez les receveurs de sang à Kinshasa-est, République démocratique du Congo. Médecine Tropicale, 61, 139-142.

[14] Ndiaye, P., Diedhiou, A., Ly, D. and Tal-Dia, A. (2008) Prévalence du VIH/sida chez les clients du centre de dépistage volontaire, anonyme et d'accompagnement de Pikine-Guédiawaye, au Sénégal. Médecine Tropicale, 68, 277-282.

[15] Tall-Sall, A. (2007) Etude Evaluative de la Prévention de la Transmission Mère Enfants du VIH au niveau des districts sanitaire de Mbao et de Rufisque (Sénégal) [Mémoire d'épidemiologie], Université Cheikh Anta Diop de Dakar; Institut de Santé et Développement.

[16] Conseil national de lute contre le sida (2016) Enquête nationale de surveillance combinée (ENSC) 2015. CNLS.

[17] Bouyer, J., et al. (2009) Epidémiologie Principes et méthodes quantitatives. Lavoisier, 498 p. 